\title{
Commentary: Crossing off CROSS for treatment of esophageal adenocarcinoma
}

\author{
Daniela Molena, MD
}

The invited opinion from De Silva Sewastjanow and colleagues ${ }^{1}$ stimulates reflection on the treatment of esophageal cancer and highlights how little progress has been made during the past decade. ${ }^{1}$ The authors applauded the Chemoradiotherapy for Esophageal Cancer followed by Surgery Study (CROSS) regimen, ${ }^{2}$ then critiqued it, and then finally suggested we stick with it until we find something better-at last we can now give adjuvant immunotherapy!

I agree that novel therapeutic strategies and moretargeted approaches to treat patients with esophageal cancer are needed. However, the first step in moving away from what the authors call "empiricism" is looking beneath the surface of recent trials because the devil is in the details.

One key discovery of the past decade is that esophageal adenocarcinoma (EAC) and squamous cell carcinoma are completely different entities at the molecular level. ${ }^{3}$ It is no surprise that the CROSS regimen (ie, carboplatin and paclitaxel with concurrent radiotherapy) has been disappointing for EAC because most of the benefit is derived from the radiation, to which most squamous-type cancers are fairly sensitive. EAC, instead, is prone to systemic spread, which is supported by nodal disease being the most important prognostic factor for survival. ${ }^{4}$ In the

From the Thoracic Service, Department of Surgery, Memorial Sloan Kettering Cancer Center, New York, NY.

Supported, in part, by the National Institutes of Health/National Cancer Institute Cancer Center Support Grant No. P30 CA008748.

Disclosures: Daniela Molena serves on a steering committee for AstraZeneca and as a consultant for Johnson \& Johnson, Bristol Myers Squibb, Merck, Boston Scientific, and Genentech.

The Journal policy requires editors and reviewers to disclose conflicts of interest and to decline handling or reviewing manuscripts for which they may have a conflict of interest. The editors and reviewers of this article have no conflicts of interest.

Received for publication Jan 14, 2022; revisions received Jan 14, 2022; accepted for publication Jan 18, 2022; available ahead of print Jan 22, 2022.

Address for reprints: Daniela Molena, MD, Thoracic Service, Department of Surgery, Memorial Sloan Kettering Cancer Center, 1275 York Ave, New York, NY 10065 (E-mail: molenad@mskcc.org).

J Thorac Cardiovasc Surg 2023;165:906-7

$0022-5223 / \$ 36.00$

Copyright (c) 2022 by The American Association for Thoracic Surgery

https://doi.org/10.1016/j.jtcvs.2022.01.021

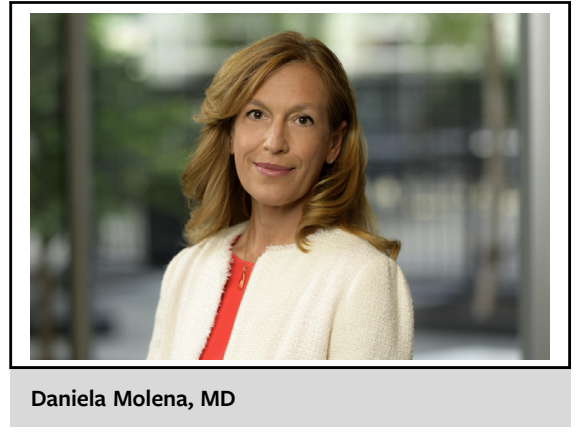

CENTRAL MESSAGE

Although CROSS retains a role for esophageal squamous cell carcinoma, better systemic options exist for adenocarcinoma, for which high-quality surgical resection remains a mainstay of treatment.

Neoadjuvant Trial in Adenocarcinoma of the Esophagus and Esophago-Gastric Junction International Study, in fact, which enrolled only patients with EAC, 3-year survival was similar between patients treated with chemoradiation and patients treated with perioperative chemotherapy, despite the higher rate of pathological complete response with chemoradiation. ${ }^{5}$ Most patients in this trial received epirubicin, cisplatin, and capecitabine (ECX) therapy, to which 5-fluorouracil, leucovorin, oxaliplatin, and docetaxel (FLOT) therapy has already proved superior. ${ }^{6}$ Moreover, the patients enrolled in the FLOT trial had moreaggressive disease than those in CROSS or the Neoadjuvant Trial in Adenocarcinoma of the Esophagus and EsophagoGastric Junction International Study (ie, higher rates of nodal disease, T4, and signet cell cancers). Therefore, if the CROSS regimen and ECX have similar outcomes but FLOT is better than ECX (even with worse disease), it seems reasonable to assume that FLOT may be better than the CROSS regimen. Data from CALGB 80803 and my institution further confirm that carboplatin-paclitaxel is a suboptimal regimen to achieve micrometastatic control in EAC. ${ }^{7,8}$ Radiation may improve local control in cases of lower-quality surgical resections (almost half of patients in the CROSS trial underwent transhiatal esophagectomy!), but the prospect of preserving the esophagus through the use of chemoradiation-which the authors argue is possible - appears to be a mirage as elusive as the meaning

Tarch 2023 
of clinical complete response. Let us not forget that the heavy lifting in the treatment of esophageal cancer is done by surgical resection and that the addition of either perioperative chemotherapy or chemoradiation adds a mere $10 \%$ to $15 \%$ benefit to surgery alone. Finally, adjuvant immunotherapy may not be as miraculous for all comers as first advertised because a real benefit is seen only in patients with a programmed death-ligand $1 \mathrm{com}$ bined positive score $>5$.

I remain optimistic that we will soon be able to offer every patient a personalized treatment plan based on cancer type, tumor genetics, circulating DNA, and patient preference. But for the time being, let us stop using CROSS to treat EAC because we have better systemic options with or without radiotherapy.

\section{References}

1. De Silva Sewastjanow M, Rogers JE, Hofstetter WL, Ajani JA. Esophageal cancer: is the CROSS strategy ready for history books? J Thorac Cardiovasc Surg. 2023; 165:901-5.

2. van Hagen P, Hulshof MC, van Lanschot JJ, Steyerberg EW, van Berge Henegouwen MI, Wijnhoven BP, et al. Preoperative chemoradiotherapy for esophageal or junctional cancer. N Engl J Med. 2012;366:2074-84.
3. Cancer Genome Atlas Research Network. Integrated genomic characterization of oesophageal carcinoma. Nature. 2017:541:169-75.

4. Ronellenfitsch U, Schwarzbach M, Hofheinz R, Kienle P, Nowak K, Kieser M Predictors of overall and recurrence-free survival after neoadjuvant chemotherapy for gastroesophageal adenocarcinoma: pooled analysis of individual patient data (IPD) from randomized controlled trials (RCTs). Eur J Surg Oncol. 2017;43: 1550-8.

5. Reynolds JV, Preston SR, O'Neill B, Lowery MA, Baeksgaard L, Crosby T, et al Neo-AEGIS (Neoadjuvant trial in Adenocarcinoma of the Esophagus and Esophago-Gastric Junction International Study): preliminary results of phase III RCT of CROSS versus perioperative chemotherapy (modified MAGIC or FLOT protocol) (NCT01726452). J Clin Oncol. 2021;39(15 suppl):4004.

6. Al-Batran SE, Homann N, Pauligk C, Goetze TO, Meiler J, Kasper S. Perioperative chemotherapy with fluorouracil plus leucovorin, oxaliplatin, and docetaxel versus fluorouracil or capecitabine plus cisplatin and epirubicin for locally advanced, resectable gastric or gastro-oesophageal junction adenocarcinoma (FLOT4): a randomised, phase 2/3 trial. Lancet. 2019;393:1948-57.

7. Goodman KA, Ou FS, Hall NC, Bekaii-Saab T, Fruth B, Twohy E. Randomized phase II study of PET response-adapted combined modality therapy for esophageal cancer: mature results of the CALGB 80803 (Alliance) trial. J Clin Oncol. 2021;39:2803-15.

8. Carr RA, Hsu M, Harrington CA, Tan KS, Bains MS, Bott MJ, et al. Induction FOLFOX and PET-directed chemoradiation for locally advanced esophageal adenocarcinoma. Ann Surg. August 13, 2021 [Epub ahead of print].

9. Kelly RJ, Ajani JA, Kuzdzal J, Zander T, Van Cutsem E, Piessen G, et al. Adjuvant nivolumab (NIVO) in resected esophageal or gastroesophageal junction cancer (EC/GEJC) following neoadjuvant chemoradiotherapy (CRT): expanded efficacy and safety analyses from CheckMate 577. J Clin Oncol. 2021;39(15 suppl):4003. 